\title{
RUPA AND FORMER PARTNERS: CUTTING THE GORDIAN KNOT WITH CONTINUING PARTNERSHIP ENTITIES
}

\author{
ROBERT W. HillMaN*

\section{INTRODUCTION}

Gordius, being made king, dedicated his wagon to the deity of the oracle, and tied it up in its place with a fast knot. This was the celebrated Gordian knot, which, in after times it was said, whoever should untie should become lord of all Asia. Many tried to untie it, but none succeeded, till Alexander the Great, in his career of conquest, came to Phrygia. He tried his skill with as ill success as others, till growing impatient he drew his sword and cut the knot. When he afterwards succeeded in subjecting all Asia to his sway, people began to think that he had complied with the terms of the oracle according to its true meaning.

The most sweeping change brought about by the Revised Uniform Partnership Act ("RUPA") is the treatment of partnerships as entities rather than aggregates of their members. ${ }^{2}$ The objective of securing entity status for partnerships served as a steady beacon guiding the efforts of RUPA's drafters in their wholesale revision of the Uniform Partnership Act (the "UPA"), a uniform act that had remained remarkably free of change since its approval by the National Conference of Commissioners on Uniform State Laws more than eighty years ago. ${ }^{4}$ Support for treatment of partnerships as entities has been virtually unanimous among recent commentators, ${ }^{5}$ and although the reform was

Copyright @ 1995 by Robert W. Hillman

* Professor of Law, University of California, Davis.

1. ThOMAS BulfinCH, MYTHOLOGY 48 (Fuller abridged ed. 1959).

2. See, e.g., REVISED UNIF. PARTNERSHIP ACT $\$ 201$ \& cmt. (last amended 1994), 6 U.L.A. 280, 295 (Supp. 1995) ("A partnership is an entity distinct from its partners."; "RUPA embraces the entity theory of the partnership.").

3. See UPA Revision Subcommittee of the Committee on Partnerships and Unincorporated Business Orgs., Should the Uniform Partnership Act be Revised?, 43 BUS. LAW. 121, 123-24 (1987) (influential report urging revision of the UPA and incorporation of entity theory wherever possible). But see Donald J. Weidner \& John W. Larson, The Revised Uniform Partnership Act: The Reporters' Overview, 49 Bus. LAw. 1, 3 (1993) (claiming the drafting committee began its work without a preference for treating partnerships as entities rather than aggregates of their members).

4. Some UPA provisions treat partnerships as entities. See, e.g., UNIF. PARTNERSHIP ACT $\S \S 8(3)$, 9, 10(1) (last amended 1914), 6 U.L.A. 3, 115, 155 (1969) (acquiring property in partnership name; partner is an agent of the partnership; conveyance of real property in partnership name). For the most part, however, the UPA advances an aggregate view of partnerships. See, e.g., id. $\$ \S 6(1), 15,29,6$ U.L.A. at 22, 174, 364 (defining partnership as an "association" of partners; joint and several liability of partners; defining dissolution as a change in the relationship among partners).

5. But cf. Gary S. Rosin, The Entity-Aggregate Dispute: Conceptualism and Functionalism in Partnership Law, 42 ARK. L. REV. 395, 466 (1989) (arguing for a functional aggregate rather than conceptual entity approach and concluding: "The UPA's existing functional approach is exactly what is called for by modern corporation law scholars. It does not bother with a 'partnership entity,' but instead looks to the underlying relationships and emphasizes the centrality of the joint business. Thus, 
said to offer a number of advantages, none was asserted more widely than the greater stability it would offer the partnership form of organization. ${ }^{6}$ The ease with which partnerships may be dissolved under the UPA, it has been suggested, not only destabilizes relationships among partners but also causes real mischief in partnership relationships with third parties. ${ }^{7}$

Addressing concerns over destabilization, RUPA allows certain partnerships to continue, without dissolution, after the withdrawal of one or more of their members. No longer will qualifying partnerships be required to dissolve, wind up, and re-form with the withdrawal of each member. By allowing the partnership entity to survive the withdrawal of its members, RUPA attempts to accord to the partnership a stability that had been denied under the UPA. ${ }^{8}$ Implicit in the reform is the idea that the withdrawing partner and the partnership may enjoy a "clean break" in their relationship.

The concept of a partnership as an entity rather than a mere aggregate of its members borrows from the corporate model of business associations. In important ways not fully recognized by RUPA, however, it is far more difficult to sever ties among participants in a partnership than in a corporation. To a significant extent, the distinction is grounded in fundamental differences, affirmed by RUPA, between the partnership and corporate forms of organization. The joint and several liability of a partner, for example, is a vestige of the aggregate theory of partnerships retained by RUPA. ${ }^{9}$ Responsibility for

it is ironic that the UPA revision process seems to be moving partnership law in exactly the opposite direction by enshrining the entity concept."); Donald J. Weidner. The Revised Uniform Partnership Act Midstream: Major Policy Decisions, 21 U. TOL. L. REV. 825, 832 (1990) ("The resort to the general theory of the business organization is all too often a substitute for analysis. . . I enthusiastically support RUPA's move closer to an entity theory, but do not believe the theory should short circuit policy analysis. There is no reason why the logic of the entity theory should be any more ineluctably applied in the partnership area than in the corporate area.").

Earlier, the debate between the entity and the aggregate camps was lively. See, e.g., Judson A. Crane, The Uniform Partnership Act-A Criticism, 28 HARV. L. REV. 762, 766-68 (1915) (arguing the aggregate approach cannot be applied consistently); William D. Lewis, The Uniform Partnership Act-A Reply to Mr. Crane's Criticism, 29 HARV. L. REV. 158 (1915) (defending the UPA's rejection of the entity theory).

6. See, e.g., J. Dennis Hynes, The Revised Uniform Partnership Act: Some Comments on the Latest Draft of RUPA, 19 FLA. ST. U. L. REV. 727, $759 \mathrm{n} .137$ (1992) (restricting automatic dissolution is a "laudable consequence" of shift to entity theory); Weidner \& Larson, supra note 3, at 3 (asserting that entity treatment will give partnerships greater stability); see also 1 ALAN R. BROMBERG \& LARRY E. RIBSTEIN, BROMBERG AND RIBSTEIN ON PARTNERSHIP \& 1.03, at 1:42 (1994) (arguing "the same pragmatic considerations . . . that justify entity treatment of corporations support the same treatment for partnerships").

7. See, e.g., Weidner \& Larson, supra note 3, at 4-5. The case most frequently cited as illustrating the need for change in the UPA's dissolution provisions is Fairway Development Co. v. Title Insurance Co., 621 F. Supp. 120 (N.D. Ohio 1985), where a dissolution caused by the change in membership of a partnership denied the remaining partners standing to sue for breach of a title guaranty policy. See, e.g., Weidner \& Larson, supra note 3, at 4 (suggesting the result in the case was unjust). It appears, however, that the Fairway Development partnership was terminable at will, and if that was the case, it is doubtful that RUPA would change the result in the case. See infra text accompanying notes 32-39.

8. See RUPA $\$ 601 \mathrm{cmt} .1,6$ U.L.A. at 322 (Supp. 1995) ("The entity theory of partnership provides a conceptual basis for continuing the firm itself despite a partner's withdrawal from the firm.").

9. See RUPA \& 306, 6 U.L.A. at 306 (Supp. 1995) (providing for joint and several liability); see also id. $\$ 201 \mathrm{cmt}$., 6 U.L.A. at 295 (Supp. 1995) (recognizing by means of a "but see" citation that joint 
partnership obligations extends beyond the partnership entity to the partners themselves and, importantly, cannot be extinguished as to a particular partner through the simple expedient of that partner's withdrawal from the partnership. ${ }^{10}$ Moreover, although liabilities are relevant in valuing the interest of a withdrawing partner for purposes of a buyout, reducing the buyout price to reflect the partner's proportionate amount of liabilities does not foreclose later third-party claims against the former partner and may undermine the assumptions on which a buyout is based. ${ }^{11}$ At least as to liabilities in the form of claims against present and former partners, RUPA adopts an aggregate view that undermines its more general and dramatic attempts to treat partnerships as entities.

In other ways, RUPA departs from the corporate entity model as a matter of choice rather than because of fundamental structural differences between partnerships and corporations. One of the more interesting departures keys on the link (or lack of a link) between status as a partner and status as a holder of an economic interest in the partnership. If one can imagine "withdrawal" from a corporation, the event would be marked by sale of shares in the corporation and consequent cessation of shareholder status. ${ }^{12}$ RUPA's continuity provisions, on the other hand, decouple status as a partner from an individual's economic interest in the partnership. ${ }^{13}$ Withdrawal from a partnership may occur, for example, before-perhaps substantially before-settlement of the dissociating partner's interest under RUPA's buyout provisions. ${ }^{14}$ Moreover, as noted above, even the buyout of the former partner's interest in assets of the partnership does not close the books with finality because of the possibility of later third-party claims against the former partner. ${ }^{15}$ Although postwithdrawal liabilities are unavoidable aspects of partnerships, RUPA's continuity provisions allowing partnerships to survive changes in membership-with virtually no

and several liability is inconsistent with an entity view of the partnership). Although joint and several liability has long been one of the principal characteristics of general partnerships, the recent development of the limited liability partnership reveals strong support to limit the joint and several liability of partners. Similar goals explain the surge in popularity of limited liability companies.

10. See id. \& 703(a), 6 U.L.A. at 273.

11. See infra notes $91-98,107-113$ and accompanying text.

12. See, e.g., MODEL BUSINESS CORP. ACT \& 1.40(22) (1994) (defining a shareholder as "the person in whose name shares are registered in the records of a corporation or the beneficial owner of shares to the extent of the rights granted by a nominee certificate on file with a corporation"). Installment sales may involve a similar decoupling of shareholder status from financial interest. See, e.g., MODEL STAT. CLOSE CORP. SUPP. $\$ 42$ (1984) (providing for avoidance of judicial dissolution through purchase of shares and requiring delivery of all shares upon receipt of the full purchase price or the first installment of the purchase price). Still, installment purchases of shares would normally commence only after the purchase price is established. RUPA, in contrast, provides for immediate cessation of partner status upon withdrawal even though the buyout price will not be determined until later. See infra text accompanying notes $100-01$.

13. However, because valuation is as of the date of dissociation and only interest accrues thereafter, the dissociated partner no longer has an equity interest tantamount to that of the continuing partners.

14. See infra part $\mathrm{V}$.

15. Indeed, a basic but often overlooked feature of partnership law is the difficulty of terminating third-party claims against former partners. See infra part VI. 
disruption or involvement of third parties-likely will increase the frequency with which such claims are asserted.

Rather than cleverly untying or even dramatically slicing the Gordian knot that binds individuals associated in partnership, RUPA's withdrawal and continuity provisions simply transform the relationship between the partnership and the withdrawing partner and create lingering ties between individuals formerly associated in partnership. This article explores the nature of those ties and evaluates the hidden costs of continuity that RUPA imposes on withdrawing partners.

II

\section{OPTING FOR CONTINUITY UNDER RUPA}

Not all RUPA partnerships survive the withdrawal of one or more of their members. The most basic, and in all likelihood prevalent, form of partnership-the at-will partnership operating without a partnership agreement-dissolves, winds up its affairs, and liquidates its assets upon the withdrawal of a single partner. ${ }^{16}$ RUPA, like the UPA, renders the partnership at will a fragile and unstable form of business association. The point that RUPA does not change the ease with which large numbers of partnerships may be dissolved is easily disguised by the emphasis RUPA and its supporters place on the entity theory of partnerships.

Still, many RUPA partnerships will achieve continuity unattainable under the UPA. Indeed, the scope of the continuity option under RUPA is greater than may appear at first glance. RUPA's continuity provisions have direct and obvious applicability to partnerships formed for a definite term or particular undertaking ("term partnerships"). As is discussed below, however, even the at-will partnership may be able to achieve under RUPA a level of continuity that the UPA simply will not allow.

\section{A. Continuity and Term Partnerships}

Partnerships that achieve continuity under RUPA do so by means of an agreement among the partners. Specifically, an agreement establishing a partnership term or undertaking renders a withdrawal prior to the expiration of the agreed term "wrongful" and allows the partnership to continue after the withdrawal without dissolution or winding up. ${ }^{17}$ Although the UPA does allow

16. See RUPA § 801(1), 6 U.L.A. at 335 (Supp. 1995).

17. RUPA defines as "wrongful" either a dissociation in breach of the partnership agreement or a dissociation from a fixed term partnership prior to the expiration of an express provision. RUPA $\S 602,6$ U.L.A. at 325 (Supp. 1995). RUPA's assignment of the "wrongful" label to withdrawals that occur prior to the expiration of an agreed term is consistent with the UPA. More clearly than the UPA, however, RUPA also treats as wrongful withdrawal actions that are otherwise violative of partnership agreements, which raises the possibility that a dissociation from an at-will partnership may be wrongful and therefore subject the withdrawing partner to liability for damages. For an analysis of wrongful dissolutions under the UPA, see Robert W. Hillman, The Dissatisfied Participant in the Solvent 
for continuity of the partnership's business without liquidation following wrongful dissociation, it treats the original partnership as dissolved and replaced by a successor partnership. ${ }^{18}$ RUPA, on the other hand, permits continuation of the original partnership entity for the balance of the agreed term or undertaking.

Because RUPA conditions continuity on an underlying agreement, the existence of the requisite agreement may be a frequent point of controversy. Agreements establishing a term or undertaking may be express or implied, ${ }^{19}$ and disputes over the existence of such agreements have been a steady source of litigation under the UPA. ${ }^{20}$ Because RUPA may condition survival of the partnership entity on existence of an agreement establishing a term or undertaking, it is likely that controversies concerning the status of associations as term partnerships rather than at-will partnerships will be even more common under RUPA than they have been under the UPA.

\section{B. Perpetual At-Will Partnerships}

May RUPA partnerships other than term partnerships survive the withdrawals of their members? Although RUPA does not expressly apply its continuity provisions to "partnerships at will," which it defines as all partnerships other than those formed for a term or undertaking, ${ }^{21}$ it provides the mechanism by which the "will" effectively may be collectivized. Thus, at-will partnerships may achieve continuity comparable to (or perhaps even greater than) that of term partnerships.

To be specific, consider a partnership formed under an agreement providing for its continued existence until a majority of partners approve dissolution and winding up; partners are free to withdraw, but such actions will not trigger dissolution and winding up. The partnership is not a term partnership because its duration is keyed neither to a fixed term nor to a particular undertaking. It also is not, at least in the minds of its members, the classic at-will partnership that does not survive a single member's expression of will to dissolve the partnership. Rather, the partnership finds some middle ground between the extremes of partnerships with lives defined specifically and partnerships terminable at the instance of any individual member.

The partnership that is not dissolved after the passage of a specified time or occurrence of a specific event, but that is terminable only by the exercise of a

Business Venture: A Consideration of the Relative Permanence of Partnerships and Close Corporations, 67 MinN. L. REV. 1, 11-14 (1982) [hereinafter Hillman, Dissatisfied Participant]; Robert W. Hillman, Misconduct as a Basis for Excluding or Expelling a Partner: Effecting Commercial Divorce and Securing Custody of the Business, 78 Nw. U. L. REV. 527, 537-38 (1983) [hereinafter Hillman, Misconduct].

18. See UPA $\$ 38,6$ U.L.A. at 456-57 (Supp. 1995).

19. See RUPA \& 101(5), 6 U.L.A. at 285 (defining the partnership as the "written, oral, or implied" agreement among the partners). But cf. id. cmt. (noting that any agreement must be established by "clear evidence").

20. See generally Hillman, Dissatisfied Participant, supra note 17, at 16-27.

21. See RUPA \& 101(6), 6 U.L.A. at 285 (Supp. 1995). 
collective (rather than an individual) will, is a popular form of partnership, particularly among individuals associated in professional practices. ${ }^{22}$ Desires of partners notwithstanding, the UPA accords no recognition to contractual restrictions on the right of a single partner to cause a dissolution of the partnership, ${ }^{23}$ which is a somewhat surprising stance in light of the deference the act generally shows to those desiring to contract around its provisions. Like the UPA, RUPA subordinates most of its provisions to contrary agreements among the partners, ${ }^{24}$ but unlike the UPA, RUPA allows partners to bargain for continuity by contractually waiving the ability of a single partner to cause a dissolution of the partnership. ${ }^{25}$ By seemingly giving life to antidissolution agreements, RUPA allows the creation of a type of at-will partnership that will survive the withdrawals of individual members and enjoy continuity of life.

\section{Ex Post Fixes to Planning Lapses: Unringing the Dissolution Bell}

Even if partners did not have the foresight to contract ex ante for continuity, RUPA allows the dissolution of a partnership in the winding-up phase to be unwound (for want of a better term) upon a unanimous vote of the partners, including any dissociating partner other than a wrongfully dissociating partner. ${ }^{26}$ The decision to unwind a dissolution will restore the scope of the partnership's activities from winding up to normal ${ }^{27}$ but will not, it seems, operate to annul or revoke the earlier dissolution. ${ }^{28}$

In partnerships without existing agreements concerning duration, the option of unwinding a dissolution may significantly enhance the leverage of dissociating partners in negotiating partnership buyouts of their interests. ${ }^{29}$ As between nondissociating and dissociating partners, typically the former will desire

22. See generally RoBert W. Hillman, HILlMAN ON LAWYeR MOBILITY $\$ 4.3 .2 .3$ (1994).

23. The UPA allows a partner to dissolve by express will even if the dissolution is wrongful because it contravenes the partnership agreement. See UPA $\$ 31(2), 6$ U.L.A. at 376 . The distinction is between the power to dissolve (which partners always have under the UPA) and the right to dissolve. See generally, Hillman, Dissatisfied Participant, supra note 17, at 8-33.

24. See RUPA $\$ 103,6$ U.L.A. at 288 (Supp. 1995) (agreement governs relations among the partners; RUPA provisions that may not be varied by agreement among partners).

25. Id. $\$ 801(1), 6$ U.L.A. at 335 (Supp. 1995) (providing that dissolution of an at-will partnership is caused by notice of dissociation by express will, is not listed in $\S 103$ (b), 6 U.L.A. at 288 (Supp. 1995), and therefore may be varied by agreement). The power to withdraw, however, is "immutable" under RUPA and cannot be waived by agreement. See id. $\$ \S 103(b)(6), 601 \mathrm{cmt}$. 2, 6 U.L.A. at 289, 323 (Supp. 1995).

26. See id. $\$ 802$ (b), 6 U.L.A. at 338 (Supp. 1995). Additional disputes may arise over defining the point at which winding up is completed and annulment of dissolution is no longer possible.

27. See id. $\S 802$ (b) cmt. 3, 6 U.L.A. at 338 (Supp. 1995).

28. RUPA thus falls short of adopting the revocation of dissolution procedure set forth in the Revised Model Business Corporation Act. See MODEL BusINESS CORP. ACT $\$ \S 14.04,14.04(e)$ (1994) ("When the revocation of dissolution is effective, it relates back to and takes effect as of the effective date of the dissolution and the corporation resumes carrying on its business as if dissolution never occurred."). This creates uncertainty concerning the effect of unwinding a partnership dissolution on agreements with third parties that assign consequences to a dissolution (for example, a loan agreement that provides for acceleration of payments upon a partnership dissolution).

29. RUPA buyout provisions, of course, are inapplicable to dissolved partnerships that are winding up. 
continuation of the original partnership, while the latter will be adverse, or at best neutral, to continuity. One response of partners desiring continuity may be to attempt to exclude a dissociating partner from the vote by characterizing the dissociation as "wrongful." ${ }^{30}$ Failing that ${ }^{31}$ the price of achieving continuity at the winding-up phase, accordingly, will likely be seen in the buyout price paid to the dissociated partner.

\section{A Concluding Thought on Confusion over Continuity and the Surprising Durability of Fairway Development}

The above discussion has considered the applicability of RUPA's continuity provisions to at-will partnerships operating under antidissolution agreements. Although RUPA's default rule, applicable in the absence of agreements to the contrary, denies continuity for at-will partnerships, partners may assume, incorrectly, that all partnerships qualify as continuing entities that survive member withdrawals. Indeed, even the official commentary accompanying RUPA shows some confusion on this score.

Consider the effect of RUPA's reforms on a case often cited as evidence of the need for reform of the UPA. In Fairway Development Co. v. Title Insurance Co. of Minnesota ${ }^{32}$ a partnership consisting of three individuals secured a title insurance policy. Later, two of the partners withdrew and were replaced by a new partner. Finding that the withdrawals constituted a dissolution of the first partnership and that the continuation of the venture was through a second partnership, the court held that second partnership was not in privity with the title insurer and therefore lacked standing to maintain an action against the insurer.

Fairway Development is a rather unexceptional case on the law but serves as a useful illustration of the problems that may arise from "technical" dissolution of a partnership caused by a change in its membership. As noted, proponents of RUPA's continuity provisions have used the case as evidence of the need to accord partnerships entity status and thereby avoid dissolution each time a partner withdraws. ${ }^{33}$ Along this line, consider the reasoning of the Official Comment:

Giving clear expression to the entity nature of a partnership is intended to allay previous concerns stemming from the aggregate theory, such as the necessity of a deed to convey title from the "old" partnership to the "new" partnership every time there is a change of cast among the partners. Under RUPA, there is no "new" partnership

30. See supra notes 17-19 and accompanying text.

31. The "failing" of "that" may not be certain for some time if the dissociated partner wishes to contest characterization of the dissociation as wrongful. Ambiguity over the status of the original partnership is likely to be of considerable concern to partners desiring continuity.

32. 621 F. Supp. 120 (N.D. Ohio 1985).

33. See, e.g., RUPA $\$ 201$ cmt., 6 U.L.A. at 295 (Supp. 1995); J. DENNIS HyNES, AGENCY AND PARTNERSHIP 580 (1994) ("The Fairway Development case caused consternation in legal circles and apparently added substantially to the impetus to adopt RUPA."); Weidner \& Larson, supra note 3, at 4 (Fairway Development applied the "strict logic of dissolution even though justice seemed to require otherwise."). 
just because of membership changes. That will avoid the result in cases such as Fairway Development Co. ..., which held that the "new" partnership resulting from a partner's death did not have standing to enforce a title insurance policy issued to the "old" partnership. ${ }^{34}$

The Comment itself makes a huge assumption concerning the scope of RUPA's continuity provisions. Nothing in the Fairway Development opinion suggests that the partnership was formed with any agreement as to duration. ${ }^{35}$ Absent such an agreement, the partnership was of the garden-variety at-will type, for which RUPA's continuity provisions would have no direct applicability. Admittedly, RUPA does create continuity options not available under the UPA. Under RUPA, the original partners could have achieved continuity in the face of membership changes through establishment of a term partnership or a perpetual at-will partnership. ${ }^{36}$ Absent a prior agreement, the partners could by unanimous vote agree to unwind the dissolution and continue the original partnership. $^{37}$ Expanding bargaining options, however, is not the same as extending by statute entity status to all partnerships. Absent some agreement that would change RUPA's default mode, the withdrawals from the original Fairway Development partnership would cause a dissolution of the original partnership under RUPA, as it did under the UPA. That being the case, the Official Comment falsely claims that RUPA "will avoid the result in cases like Fairway Development Co."38 and thereby adds to confusion over the scope of RUPA's continuity provisions. ${ }^{39}$

\section{III}

\section{FUZZY DEPARTURES: STATUTORY AMBIGUITY AND STRATEGIC OPPORTUNITY}

More so than under the UPA, defining the exact point at which withdrawal occurs is a critical exercise under RUPA. Withdrawal under the UPA does not mark the cessation of an individual's status as a partner but simply moves the partnership into the winding-up phase of its existence. ${ }^{40}$ Dissociation from a partnership operating under RUPA's continuity provisions, on the other hand, marks the abrupt termination of the withdrawing partner's status as a partner (for most purposes), ${ }^{41}$ provides the relevant date for valuing the interest of the

34. RUPA $\S 201 \mathrm{cmt}, 6$ U.L.A. at 295 (Supp. 1995) (emphasis added).

35. The existence of a possible implied agreement as to duration of the partnership was not discussed.

36. See supra notes $16-25$ and accompanying text.

37. See supra notes $26-31$ and accompanying text.

38. RUPA $\$ 201 \mathrm{cmt}$., 6 U.L.A. at 295 (Supp. 1995).

39. Of course, RUPA would allow the partners in the first Fairway Development partnership to opt for continuity by agreeing to a fixed term or perpetual at-will partnership.

40. See UPA $\S 30,6$ U.L.A. at 367.

41. See, e.g., RUPA $\$ \$ 403$ (b), 603, 702, 6 U.L.A. at 312, 327, 331 (Supp. 1995) (dissociated partners continue to have access to books and records but only for the period during which they were partners; dissociation terminates the right to participate in management and sharply limits loyalty obligations; dissociated partner may bind the partnership only if third party does not know of 
former partner, ${ }^{42}$ and marks the beginning of the point from which the former partner, in theory, is entitled to indemnification from subsequently arising liabilities. ${ }^{43}$

Under RUPA, dissociation occurs with "the partnership's having notice of the partner's express will to withdraw as a partner or on a later date specified by the partner." 44 Having notice, of course, is not the same as giving notice, which is a distinction that may be of some importance when dissociations are sudden. Under RUPA, a person has notice of a fact when the person "knows of it; has received a notification of it; or has reason to know it exists from all of the facts known to the person at the time in question." ${ }^{45}$ When, then, does a person receive notification? This occurs, again under RUPA, when the notification "comes to the person's attention; or is duly delivered at the person's place of business or at any other place held out by the person as a place for receiving communications." ${ }^{46}$ Notification of a partner of a "fact relating to the partnership" is effective notification of the partnership. ${ }^{47}$ The partnership agreement, however, may specify that notice of withdrawal be in writing, ${ }^{48}$ which surely will raise numerous controversies concerning the effect, if any, of oral notice when written notice is required.

Despite RUPA's considerable effort to define the point at which notification of dissociation occurs, the conduct of many partners will not fit within the rather ritualistic framework created by the new Act. What is the effect for example, of the outburst, "I quit," or "I'm out of here"? If such a statement is expressed to another partner, has the partner dissociated from the partnership entity at the moment of the utterance? Or is the statement a mere expression of intent to withdraw at some time in the future? Can the partner have a change of heart and retract the statement? Must the express will of a partner be reflected in a statement of some sort, or may it be inferred from the conduct of the partner? If the will of an individual may be expressed through conduct, what is the effective date of dissociation when a partner abandons a partnership? How is

dissociation and believes the dissociated partner is still a partner). Cf. id. $\S 601 \mathrm{cmt} .1,6$ U.L.A. at 323 (Supp. 1995) ("[I]t is more useful to think of a dissociated partner as a partner for some purposes, but as a former partner for others.").

42. See RUPA § 701(b), 6 U.L.A. at 328 (Supp. 1995). Moreover, interest must be paid from the date of dissociation to the date of payment. Id. Under the UPA, the date of withdrawal (i.e., dissolution) is the relevant date for valuation if the dissolution is wrongful, and the other partners elect to continue the business for the balance of the agreed term or undertaking. See UPA \& 38(2)(b), 6 U.L.A. at 456.

43. RUPA § 701(d), 6 U.L.A. at 328 (Supp. 1995); see also id. §§702-703 (limited power to bind partnership for two years following dissociation; liability for certain transactions entered into within two years of dissociation). Moreover, wrongful dissociation of a partner from a fixed-term partnership entitles the remaining partners, upon vote of half their number within 90 days of the date of dissociation, to wind up the partnership business. See id. $\S 801$ (2)(i), 6 U.L.A. at 335 (Supp. 1995).

44. Id. \$ 601(1), 6 U.L.A. at 322.

45. Id. \$ $102(\mathrm{~b}), 6$ U.L.A. at 287.

46. Id. § 102(d), 6 U.L.A. at 287.

47. Id. $\$ 102(\mathrm{f}), 6$ U.L.A. at 287.

48. See id. \& 103(b)(6), 6 U.L.A. at 289. 
abandonment determined? RUPA is not writing on a clean slate, and experience under the UPA has amply demonstrated the difficulty of measuring under simple statutory formulae the words and conduct of individuals entering and exiting partnerships. ${ }^{49}$ Indeed, RUPA's formalistic views of notice provisions stand in contrast to its much more relaxed standards for entry into a partnership. ${ }^{50}$ Given the formalism of RUPA's exit notice provisions, controversies over the existence and timing of withdrawals are inevitable.

Ambiguity concerning withdrawal may give the dissociating partner, or the continuing partners for that matter, an opportunity to define ex post the most advantageous date of withdrawal. Imagine, for example, a partnership engaged in a cyclical activity such as farming. Near a harvest and at a time of economic distress for the partnership, one partner announces he is "getting out of farming and the partnership." 51 From then on, the partner devotes substantially all of his time to a new business. Over the course of the next year, the partners conduct unsuccessful discussions on the settlement of partnership affairs. By the time it is clear a settlement cannot be reached, the prospects for the partnership appear brighter and the departing partner formally announces his dissociation from the partnership, effective immediately. Had prospects for the partnership deteriorated rather than improved, the departing partner would have taken the position that the dissociation occurred at the time of his earlier statement that he was "getting out of farming and the partnership." The departing partner, in short, had every incentive to act ambiguously and thereby create for himself an option as to the timing and very existence of a dissociation.

RUPA encourages dissociation ambiguity by failing to require the withdrawing partner to take additional steps coincident with dissociation that would affirm a dissociation. The buyout provisions, for example, lie dormant until the dissociating partner makes a written demand for payment. ${ }^{52}$ In some cases, the dissociating partner may well have an incentive, in the form of rapid account settlement, to make a prompt demand for payment that activates RUPA buyout provisions. Very often, however, rapid account settlement will not be a realistic goal for the dissociating partner. ${ }^{53}$ Premature termination from a term partnership, for example, is a "wrongful" dissociation that allows

49. See, e.g., Paciaroni v. Crane, 408 A.2d 946 (Del. Ch. 1979) (dissolution by express will implied by relieving trainer-partner of responsibility and directing transfer of racing horse to new trainer); Meuret v. Meuret, 617 P.2d 918 (Or. Ct. App. 1980) (dissolution by express will implied by ceasing participation in business, use of partnership funds for personal endeavors, and establishing a competing business). See generally 2 BROMBERG \& RIBSTEIN, supra note 6, \& 7.02(c), at 7:17-:22.

50. See RUPA \& 202(a), 6 U.L.A. at 295 (Supp. 1995) ("[T]he association of two or more persons to carry on as co-owners a business for profit forms a partnership, whether or not the persons intend to form a partnership."). But see id. $\$ 601 \mathrm{cmt} .2,6$ U.L.A. at 323 ("Since no writing is required to create a partner relationship, it was felt unnecessarily formalistic, and a trap for the unwary, to require a writing to end one.").

51. The hypothetical is loosely based on Timmermann v. Timmermann, 538 P.2d 1254 (Or. 1975), decided under the UPA.

52. See RUPA \& 701(e), 6 U.L.A. at 328 (Supp. 1995); infra notes 58-59 and accompanying text.

53. See infra text accompanying notes $99-106$. 
the continuing partners to defer payment of amounts due the dissociated partner until the end of the partnership term. ${ }^{54}$ To the extent payment is deferred and the fortunes of the partnership may improve, there may be little if any point for the dissociating partner to resolve ambiguities concerning withdrawal (and termination of equity participation) by making an early demand for payment.

\section{IV}

\section{THE RUPA BUYOUT}

The price extracted under RUPA for continuing a partnership without dissolution is the buyout of the dissociated partner's interest. ${ }^{55}$ The buyout is a rough substitute for a liquidation of the partnership business followed by a satisfaction of liabilities and distribution of the net proceeds to the partners. ${ }^{56}$ It is also not necessarily a bad substitute because of the thinness of the market that may exist for partnership's assets. Sometimes, asset auctions fail to produce competitive bidding and simply provide a means for continuing partners, as the sole bidders, to cash out withdrawing partners at distress prices. ${ }^{57}$ Still, RUPA places extraordinary faith in its own ability to set forth a valuation framework that serves as an adequate substitute for sales into the market. The following discussion considers the degree to which that faith is warranted and whether RUPA's buyout provisions work to cut cleanly the ties between dissociating partners and their partnerships.

\section{A. The Buyout Process}

The RUPA buyout process begins with a written demand from the dissociated partner. ${ }^{58}$ Until the demand is made, nothing of importance happens under the RUPA process. This produces the strange result that a partner may dissociate and thereby terminate partner status through an oral

54. Id.

55. The UPA has limited buyout provisions. In the event of wrongful dissolution of a fixed-term partnership, the remaining partners are allowed to continue to possess partnership assets for the duration of the agreed term if they pay, or secure payment, of the "value of [the dissolving partner's] interest in the partnership," less certain offsets. UPA $\$ 38(2)(b), 6$ U.L.A. at 456 . No guidance is provided, however, on how "value" is to be determined.

56. RUPA's goal is that the "departing partner should get the same amount through the buyout that he or she would get if the business were wound up." Weidner \& Larson, supra note 3, at 11.

57. This statement is not inconsistent with the widely held belief that the best determinant of value is what a buyer is prepared to pay. In some partnership liquidations, however, truly competitive bidding is either discouraged or not feasible. For example, in Cude v. Couch, 588 S.W.2d 554 (Tenn. 1979), the sole bidder was a partner who also owned, outside of the partnership, the building in which the partnership's business was operated. He successfully discouraged competitive bidding by announcing he would not lease the building to anyone else. The court found no breach of fiduciary duty by the partner, although there was a spirited dissent. A few cases suggest fiduciary standards limit use of dissolution and liquidation as a means of squeezing out a partner at a bargain price. See, e.g., Page v. Page, 359 P.2d 41 (Cal. 1961). For discussion of dissolution as a squeeze out and rebargaining technique, see Robert W. Hillman, Private Ordering Within Partnerships, 41 U. MIAMI L. REV. 425, 46671 (1987).

58. RUPA $\S 701$ (e), 6 U.L.A. at 328 (Supp. 1995). 
expression of will to this effect (or even conduct evidencing such intent) but cannot commence the RUPA buyout process until a demand for payment is put into writing. In any event, the written demand launches a 120-day period ${ }^{59}$ during which the parties, ideally, will negotiate concerning the buyout price. If no agreement is reached, the partnership must tender to the dissociated partner the amount (or, if a deferred payment is authorized, an offer to pay an amount) the partnership estimates to be the buyout price. ${ }^{60}$ If the dissociated partner is dissatisfied with the partnership's estimate, she then has an additional 120 days $^{61}$ to initiate judicial action to determine the buyout price. ${ }^{62}$ The Official Comment calls this second 120-day period a "cooling off period," 63 which is an odd characterization since RUPA does not preclude initiation of judicial action immediately after receipt of the buyout price estimate.

Viewed in the most positive sense, RUPA contemplates a give-and-take process of arriving at a buyout price, with ultimate recourse to judicial valuation to resolve serious differences. The incentive for the partnership to achieve a prompt agreement on buyout price through negotiation, however, may be weak. In particular, there is no reason for the partnership to seek prompt payment of the buyout price when the dissociated partner no longer may participate in partnership affairs ${ }^{64}$ and will not enjoy, or suffer, increases or decreases in the value of the partnership that occur after the date of dissociation. To make sharing in partnership profitability until the resolution of the buyout possible, the UPA allows some withdrawing partners to elect, in lieu of interest, a share of profits attributable to the use of their property by the partnership. ${ }^{65}$ Without explanation, RUPA eliminates the UPA's profit-sharing-in-lieu-ofinterest option and reduces the status of dissociated partners to that of nonequity claimants. Accordingly, a partnership may have a strong incentive to estimate a low buyout price and defer to the extent possible resolution of differences over the buyout price. ${ }^{66}$

59. The 120-day period comes after an undefined period of possible negotiation prior to the issuance of a written demand for payment. This point is ignored in the Official Comment, which incorrectly states that the partnership must make a cash payment to the dissociated partner "within 120 days of dissociation." RUPA $\$ 701 \mathrm{cmt}$ 6.6 U.L.A. at 330 (Supp. 1995).

60. The estimate is to be accompanied by a statement of partnership assets and liabilities as of the date of dissociation, the latest available balance sheet and income statement, an explanation of how the estimated amount of the payment was calculated, and written notice that the payment is in full satisfaction of the partnership's obligation unless the dissociated partner initiates judicial action within 120 days. See RUPA $\$ 701(\mathrm{~g}), 6$ U.L.A. at 328 . Such requirements introduce a significant measure of formalism and will prove a trap for those partners not educated in RUPA's niceties. The consequences of failing to comply with the formalities, however, are not clear.

61. The magic of 120 -day periods (as opposed to 90 - or 180 -day periods) was not explained by RUPA drafters.

62. See RUPA $\S 701(i), 6$ U.L.A. at 329 (Supp. 1995).

63. See id. \$ $701 \mathrm{cmt}$ 9,6 U.L.A. at 330.

64. Or, to put it more bluntly, when the dissociated partner is not a nuisance on a day-to-day basis.

65. See UPA § 42, 6 U.L.A. at 521. See generally HillMAN, supra note 22, § 4.3.6; 2 BROMBERG \& RIBSTEIN, supra note $6, \S 7.13(\mathrm{f})$, at $7: 133-: 141$.

66. RUPA does provide some check, in theory, on a bad faith estimate of the buyout price. See RUPA $\$ 701(i), 6$ U.L.A. at 329 (Supp. 1995) (Attorneys fees and costs of appraisers or other experts 
In sum, RUPA's buyout process will spawn strategic behavior. Such behavior will not be limited to the partnership's efforts to defer payment of the buyout price. Independent of timing considerations, the partnership may be expected to determine the probable cost for the dissociated partner to pursue judicial valuation and discount the buyout price by an amount close to, but less than, the estimated litigation costs for the dissociated partner. To the extent that estimated litigation costs are small in relation to the value of the interest, the dissociated partner will not be particularly vulnerable to such a strategy. As the buyout price falls in relation to the litigation costs, however, the partnership may be able to capture a significant portion of the value of the dissociated partner's interest. For a partner whose interest is not of substantial value, RUPA's buyout process may yield a significantly smaller payout than an actual liquidation of partnership assets.

\section{B. The Buyout Price: Valuation Estimates}

Once activated, ${ }^{67}$ RUPA's buyout provisions call for a snapshot appraisal of the value of the partnership as of the date of dissociation, ${ }^{68}$ based upon the greater of liquidation ${ }^{69}$ or going-concern value, ${ }^{70}$ and a (hypothetical) liquidating distribution to the dissociated partner. ${ }^{71}$ This amount is reduced to account for damages because of wrongful dissociation and other amounts owed (whether presently or not) by the dissociated partner. ${ }^{72}$ The resulting sum is then tendered, in cash, to the dissociated partner and becomes the "undisputed minimum value of the partner's partnership interest." If the parties do not agree on price, the dissociated partner may seek judicial valuation. Although both the partnership and the court will determine buyout price under the same valuation formula and in light of the same rights of offset, the results reached by the two may be substantially different both because of the partnership's

may be assessed by the court against a party that has acted "arbitrarily, vexatiously, or not in good faith.").

67. See supra text accompanying notes 58-59.

68. See RUPA \& 701(b), 6 U.L.A. at 328 (Supp. 1995).

69. Although the Official Comment states that "liquidation value" does not mean "distress sale value," RUPA $\$ 701 \mathrm{cmt}$. 3, 6 U.L.A. at 329 (Supp. 1995), the statement has the tone of wishful thinking, because liquidation is a method of valuation often associated with just such a result. See generally Harry J. Haynsworth IV, Valuation of Business Interests, 33 MERCER L. REV. 457, 470-71 (1982).

70. The going-concern alternative allows a discounted cash flow valuation. See generally David Cohen, Comment, Valuation in the Context of Share Appraisal, 34 EMORY L.J. 117, 127-44 (1985).

71. RUPA provides:

The buyout price of a dissociated partner's interest is the amount that would have been distributable to the dissociating partnership under Section 807 (b) if, on the date of dissociation, the assets of the partnership were sold at a price equal to the greater of the liquidation value or the value based on a sale of the entire business as a going concern without the dissociated partner and the partnership were wound up as of that date.

RUPA § 701(b), 6 U.L.A. at 328 (Supp. 1995).

72. Id. $\S 701$ (c), 6 U.L.A. at 328 .

73. Id. $\$ 701 \mathrm{cmt} .6,6$ U.L.A. at 330 . 
strategic use of the estimates ${ }^{74}$ and because valuation itself is an uncertain and subjective exercise. ${ }^{75}$

Use of the phrase "value of the partner's interest" in discussing the buyout price is, perhaps, unavoidable, but it may lead to confusion. By focusing on estimated distributions following a going-concern or liquidation sale, RUPA sensibly directs the valuation inquiry away from estimates of the value of a particular partner's interest, an approach that would introduce significant complexities to the valuation inquiry. Consider, for example, the effect of joint and several liability on the valuation of a particular partner's interest by a prospective purchaser of the interest. Assuming the purchaser inherited the liability of the selling partner, ${ }^{76}$ the value of the interest should reflect the liabilities, actual and potential, assumed by the purchaser. ${ }^{77}$ As to each partnership and each partner, however, that valuation will fluctuate in response to the wealth of the purchaser and the wealth of the other partners. Value would be negatively affected, for example, if the partnership and the other partners had few assets while the purchaser had substantial wealth. ${ }^{78}$ By focusing on a top-down valuation keyed to a sale of the firm (or its assets), RUPA ignores the financial circumstances of continuing partners and therefore may produce a valuation distinct from that which would result by focusing on the value of a particular dissociated partner's interest. ${ }^{79}$

Through its buyout price provisions, RUPA is attempting to determine an amount that is equivalent to the amount that would be received by the dissociated partner if the partnership wound up its affairs and liquidated its assets. ${ }^{80}$ In fact, when the valuation question is viewed as distinct from other aspects of the buyout-such as payment timing and allowable offsets-RUPA may actually improve the position of the dissociated partner over the result that would flow from an actual liquidation. Depressants of value realized, such as thin markets and lack of competitive bidding, ${ }^{81}$ may be discounted or ignored

74. See supra notes $84-96$ and accompanying text.

75. See sources cited infra note 83 .

76. This assumption is for the sake of discussion only. As to the actual liability of a newly admitted partner, see RUPA \& 306(b), 6 U.L.A. at 306 (Supp. 1995) (no liability for obligations incurred prior to admission). Even if earlier liabilities were not assumed, liability would be unlimited for liabilities incurred after the purchase and, accordingly, the financial circumstances of the partnership and the other partners would be important to the purchaser.

77. Cf. Frank H. Easterbrook \& Daniel R. Fischel, Limited Liability and the Corporation, $52 \mathrm{U}$. CHI. L. REV. 89, 95 (1985) (discussing the function of limited liability in promoting share pricing by rendering irrelevant the wealth of other investors in a corporation).

78. Moreover, the introduction of a partner with greater wealth than the outgoing partner may increase the value of the continuing partners' interests.

79. Given the methodology, the Official Comment correctly observes that a minority discount would be inappropriate but adds: "Other discounts, such as for lack of marketability or the loss of a key partner, may be appropriate." RUPA § $701 \mathrm{cmt}$. 3, 6 U.L.A. at 329 (Supp. 1995). If "lack of marketability" refers to assets of the partnership, a discount would be appropriate, but if the reference is to the partnership interest itself, a discount would be inappropriate under RUPA's mode of valuation.

80. See supra note 56.

81. See supra note 57 and accompanying text. 
altogether when value is determined by means of an imagined rather than an actual liquidation of the business and assets of a partnership. ${ }^{82}$

A full consideration of RUPA's valuation methodology is beyond the scope of this article. ${ }^{83}$ Certain aspects of the Act's buyout provisions, however, are particularly important in evaluating the way that RUPA severs the ties between continuing partnerships and dissociated partners. These include the use of offsets in arriving at an estimate of the buyout price, a standard for the indemnification of a dissociated partner that is overinclusive, the distortions in valuation that may arise because of the manner in which liabilities are treated in arriving at a buyout price, and the availability of liberal deferral provisions that may allow a partnership to delay actual payment of a buyout price for an extended period of time. Each of these is discussed below.

\section{The Buyout Price: Offset Estimates}

A potentially significant adjustment underlying the partnership's calculation of a buyout price is the allowable offset for damages for wrongful dissociation and other amounts owing by the dissociated partner. ${ }^{84}$ RUPA defines a wrongful dissociation as either a dissociation in breach of the partnership agreement $^{85}$ or a dissociation from a fixed term partnership that is premature because it occurs prior to the expiration of the agreed term. ${ }^{86}$ Whether the dissociation is wrongful, of course, may be a contested issue, but the partnership has every incentive to assume wrongfulness for purposes of its estimates. ${ }^{87}$ Even more problematic, from the perspective of the dissociated partner, is the partnership's estimate of damages that may stem from a wrongful dissociation. Nearly a century of experience with the UPA has shown the difficulty of establishing with reasonable certainty damages suffered because of wrongful departures from partnerships. ${ }^{88}$ A partnership evaluating its own entitlement to damages, however, is likely to overcome in its own favor any doubts concerning the speculative character of damages.

82. Cf. RUPA $\S 701 \mathrm{cmt}$. 3, 6 U.L.A. at 329 (Supp. 1995) ("[T]he hypothetical selling price . . should be the price that a willing and informed buyer would pay a willing and informed seller, with neither being under any compulsion to deal.").

83. Valuation formulas of the type outlined in RUPA have a comforting appearance of objectivity, but those experienced in estimating what a business is worth will acknowledge the truly subjective and arbitrary nature of the exercise. On valuation, see generally Cohen, supra note 70, at 117; William P. Lyons \& Martin S. Whitman, Valuing Closely Held Corporations and Publicly Traded Securities with Limited Marketability: Approaches to Allowable Discounts from Gross Values, 33 BUS. LAW. 2213 (1978); Zenichi Shishido, The Fair Value of Minority Stock in Closely Held Corporations, 62 FORDHAM L. REV. 65 (1993).

84. See RUPA § 701(c), 6 U.L.A. at 328 (Supp. 1995). In addition, the partnership is entitled to offset for "all other amounts owing, whether or not presently due, from the dissociated partner to the partnership." Id.

85. See id. $\$ 602$ (b)(1), 6 U.L.A. at 325.

86. See id. $\$ 602(\mathrm{~b})(2), 6$ U.L.A. at 326.

87. Cf. id. $\$ 602 \mathrm{cmt}$. 2,6 U.L.A. at 326 (suggesting the possibility that premature withdrawal may be wrongful even if in response to misconduct).

88. See generally 2 BROMBERG \& RIBSTEIN, supra note $6, \S 7.03$ (c), at 7:35-:37. 
Apart from damages it assesses the dissociated partner, the partnership is entitled to deduct from the buyout price "all other amounts owing, whether or not presently due, from the dissociated partner to the partnership." 89 The partnership need not, however, increase the buyout price by additional amounts owed to the dissociated partner. The reasons for the asymmetrical treatment of amounts owed to the dissociated partner and to the partnership are not clear. The rule would seem to work a particular hardship when, as discussed below, the partnership elects to defer payment of the purchase price until the expiration of the agreed term. ${ }^{90}$ In such a case, dissociation may accelerate and make presently payable an obligation of the withdrawing partner at the same time the partnership is able to continue to defer amounts owed to the dissociated partner.

\section{The Buyout Price: Liability Estimates}

Liabilities of the partnership reduce the amount payable in the buyout. To protect the dissociated partner from effectively paying twice as to liabilities reflected in the buyout, RUPA requires indemnification by the partnership "against all partnership liabilities, whether incurred before or after the dissociation." Although indemnification against liabilities is not the equivalent of release from liabilities, which requires the consent of third parties, ${ }^{92}$ the combination of lowering the buyout price and protecting the dissociated partner by indemnification provides a reasonable means of distancing the withdrawing partner from known and fixed partnership liabilities.

Not all liabilities, however, are both known and fixed at the time of valuation. It is in the partnership's advantage to consider contingent liabilities in arriving at its estimate of the buyout price. ${ }^{93}$ Since a contingent liability, by definition, may or may not mature into an actual claim against the partnership, the valuation should not reflect such a liability at full face amount (even

89. RUPA $\S 701$ (c), 6 U.L.A. at 328 (Supp. 1995).

90. See infra part $\mathrm{V}$.

91. RUPA $\$ 701$ (d), 6 U.L.A. at 328 (Supp. 1995).

92. An early draft of RUPA provided that such consent may be inferred from course of dealing between a creditor and the continuing partners, see RUPA $\$ 36(\mathrm{~b})$ (1990 draft), but this provision was not included in the final version of the act. See RUPA \& 703(c), 6 U.L.A. at 332 (Supp. 1995).

93. The incentive for the partnership to estimate contingent liabilities expansively was recognized by RUPA drafters. The official comment accompanying RUPA as approved in 1993 (at the time considered a final adoption but in retrospect the penultimate action) candidly observed:

Under RUPA, the partnership has an incentive to insist that all known liabilities be taken into account since they will reduce the buyout price. The dissociating partner might prefer to ignore contingent liabilities in favor of a higher buyout price and take the chance of their ever materializing. The "known" liabilities rule, however, contemplates that all contingent or uncertain liabilities can and will be recognized in the valuation of the withdrawing partner's account, using estimates and probabilities.

UNIF. PARTNERSHIP ACT (1993) $\S 701 \mathrm{cmt}$ 4, 6 U.L.A. at 270 (Supp. 1994) (emphasis added). Although the above was not included in the final version of the official comments, the partnership still has the incentive to use only the most favorable assumptions in arriving at its estimate of the value of the dissociated partner's interest. 
assuming that amount can be ascertained). Instead, the appropriate valuation of a contingent liability will discount the claim by the probability of the contingency occurring and the claim becoming real. ${ }^{94}$ Assumptions underlying the discounting may prompt significant disagreement, as may efforts by the partnership (apparently allowed under RUPA) to consider liabilities too remote to be recognizable under general accounting standards. ${ }^{95}$

The sole purpose of estimating liabilities is to arrive at a buyout price payable to the dissociated partner. Although the passage of time eventually will eliminate any uncertainty over the amount of liabilities properly chargeable to a former partner, RUPA does not provide for a revisitation of earlier liability estimates used in the buyout calculation. From the perspective of certainty, there is an obvious advantage in closing the inquiry at the time of the estimate and determining with finality the amount owed the former partner. Still, many RUPA buyouts will be deferred until the expiration of agreed partnership terms or undertakings, ${ }^{96}$ at which point there will be much greater certainty concerning liabilities existing at the time of dissociation. It is curious that RUPA places such great stress on rapid calculation of the buyout price, even if the figure will depend in large part on estimates and actual payment will be deferred to a point when the true extent of liabilities will be known.

\section{E. The Buyout Price: Indemnification}

Until the late stages of its development, RUPA provided some disincentive (albeit limited) to unduly high partnership estimates of liabilities by excluding from the partnership's indemnification obligation liabilities unknown at the time of dissociation. ${ }^{97}$ Coupling indemnification with liabilities considered in arriving at the buyout price would be sensible because indemnification extending to a liability not reflected in the buyout price potentially would be a windfall to the dissociated partner. Indemnification, in other words, is necessary

94. Cf. Covey v. Commercial Nat'l Bank of Peoria, 960 F.2d 657, 659 (7th Cir. 1992) (debtor's assets, or lack thereof, limit the value of contingent claim); In re Xonics Photochemical, Inc., 841 F.2d 198, 200 (7th Cir. 1988) (necessity of discounting contingent liabilities for the purpose of determining insolvency).

95. See, e.g., ACCOUNTING FOR CONTINGENCIES, Statement of Financial Accounting Standards No. 5 (Fin. Accounting Standards Bd. 1978) (varying disclosure obligations based upon whether a loss contingency is probable, reasonably possible, or remote).

96. See infra text accompanying notes 99-103.

97. See RUPA $\$ 701$ (d), 6 U.L.A. at 328 (Supp. 1995) ("A partnership shall indemnify a dissociated partner against all partnership liabilities incurred before the dissociation, except liabilities then unknown to the partnership ...."). The UPA's provisions concerning protection of former partners when liquidation does not follow dissolution and the business is continued are flawed by serious inconsistencies. One provision allows avoidance of liquidation only if the continuing partners "indemnify [the withdrawing partner] against all present or future partnership liabilities." UPA $\$ 38(2)$ (b), 6 U.L.A. at 456 . Another provision gives the former partner a right "to be released from all existing liabilities of the partnership." Id. $\$ 38(2)$ (c)(II), 6 U.L.A. at 456-57. Indemnification is not the equivalent of release, and existing liabilities are not the equivalent of all present or future liabilities. On the inadequacies of the UPA's indemnification provisions, see Hillman, Misconduct, supra note 17 , at 555-56. 
only to prevent the dissociated partner from effectively being charged twice for a liability. Nevertheless, a last minute "stylistic" change to RUPA uncouples buyout price from indemnification and requires the partnership to indemnify the dissociated partner against all liabilities, including those not considered in arriving at a buyout price. ${ }^{98}$ The uncoupling is bad policy because overly generous indemnification may encourage members of a partnership in an early stage of decline to "bail out" and demand indemnification from the partnership for liabilities not fully reflected in the valuation of their interests but later asserted by third parties.

\section{$\mathrm{V}$ \\ THE DefERred Buyout}

Determination of the amount owed a dissociated partner does not necessarily trigger actual payment of the buyout price. RUPA allows the partnership to defer payment of the buyout for a variety of reasons, the most important of which is applicable to a "partner who wrongfully dissociates before the expiration of [an agreed partnership term or undertaking]." 99 In such a case, payment to the dissociated partner may be deferred (if adequately secured) until the expiration of the term or undertaking, unless the former partner establishes that earlier payment "will not cause undue hardship to the business of the partnership." 100 The result of deferring a buyout may be particularly harsh because RUPA eliminates the UPA's profits-or-interest election, ${ }^{101}$ which means not only that the wrongfully (that is, prematurely) dissociating partner is liable for damages, but also that the former partner effectively converts from an equity participant in the partnership to a creditor (perhaps for the long term) of the partnership venture. Far from accomplishing a clean break, implementation of RUPA's deferred buyout provisions may create a lasting tie between partnerships and their former partners, at least from the perspective of the latter.

The buyout may be deferred only if payable to a "partner who wrongfully dissociates before the expiration of a definite term or the completion of a particular undertaking."102 Not all wrongful dissociations justify the deferral of buyouts. Recall that RUPA defines a dissociation as wrongful if it either is in breach of the partnership agreement or is prior to the expiration of an agreed term or undertaking. ${ }^{103}$ Only the dissociation that is wrongful by virtue of

98. See RUPA § 701(d), 6 U.L.A. at 328 (Supp. 1995).

99. Id. \$ 701(h), 6 U.L.A. at 328.

100. Id. For a discussion of the hardships inherent in buyouts, see Hillman, Dissatisfied Participant, supra note 17 , at $70-72$.

101. See UPA $\$ 42,6$ U.L.A. at 521; supra text accompanying notes $64-66$. The "adequate security" may impair the ability of the partnership to secure future financing. Setting aside issues concerning the ascertainability of such damages, lowering the buyout to compensate for diminution of borrowing capacity simply shifts the costs of securing the obligation to the dissociated partner.

102. RUPA § 701(h), 6 U.L.A. at 328 (Supp. 1995).

103. See supra note 17 and accompanying text. 
being premature, however, permits a buyout deferral. In such a case, the period of the deferral may be easily established, while in other types of wrongful dissociations (that is, those that are not premature) it would be difficult to identify an appropriate period for the deferral.

An important issue not adequately addressed by RUPA is whether any dissociation prior to the expiration of the partnership term or undertaking is wrongful, at least for the purpose of deferring the buyout. Is dissociation for good reason-such as misconduct by other partners-necessarily wrongful simply because it occurs during the agreed term of the partnership? RUPA's definition of wrongful dissociation is equivocal, but it suggests an affirmative response, ${ }^{104}$ as does the Official Comment: "A partner wishing to withdraw prematurely from a term partnership for any other reason, such as another partner's misconduct, can avoid being treated as a wrongfully dissociating partner by applying to a court ... to have the offending partner expelled."105

Unfortunately, the Official Comment ignores impediments to judicial expulsion as a response to misconduct, including the time and costs associated with securing such external relief. The better view is that dissociation for cause (such as conduct of another partner that would warrant judicial expulsion of the partner) is not wrongful, but the dissociating partner must assume the risk of assessing accurately the existence of cause. If that is the case, then the Official Comment simply serves as a useful reminder of the risk of misassessment inherent in responding to misconduct by self-help (that is, dissociation) rather than judicial intervention. ${ }^{106}$

\section{VI}

\section{LATENT LIABILITIES}

Partners are jointly and severally liable for partnership obligations. ${ }^{107}$ Withdrawal from a continuing partnership, of course, does not in itself extinguish the exposure of the departing partner, ${ }^{108}$ who remains responsible not only for liabilities incurred prior to the withdrawal but also for some subsequently incurred obligations. ${ }^{109}$ The liability of the partner, combined with the lack of an expeditious means of terminating the partner's liability when the partner withdraws from a venture, is a major distinction between the partnership

104. See RUPA $\S 602$ (b)(2), 6 U.L.A. at 326 (Supp. 1995) (simply defining as wrongful a dissociation "before the expiration of the term or completion of the undertaking").

105. Id. $\$ 602 \mathrm{cmt}$. 2, 6 U.L.A. at 326.

106. But $c f$. Fisher v. Fisher, 212 N.E.2d 222 (Mass. 1965) (implying judicial intervention is the only acceptable response under the UPA to misconduct). On self-help as opposed to judicial intervention, see Hillman, Misconduct, supra note 17 , at 539-44.

107. RUPA § 306, 6 U.L.A. at 306 (Supp. 1995).

108. Id. $\$ 703(\mathrm{a}), 6$ U.L.A. at 332 .

109. See id. $\$ \$ 703$ (b), 704(c), 6 U.L.A. at 332, 333 (liability for "transaction entered into" within two years of dissociation if the third party reasonably believes the dissociated partner is a partner and does not have notice of the dissociation; providing for filing of statement of dissociation and constructive notice of dissociation). 
and corporate forms of organization and a major limitation on application of entity theory to partnerships.

When withdrawal triggers dissolution and liquidation, the scope of the partnership changes from that of an ongoing business to that of a business in the winding-up phase of its existence. ${ }^{110}$ Liabilities incurred in winding up a partnership will generally be more limited than those incurred by a continuing business. Moreover, a critical part of winding up is the identification of all liabilities and the application of proceeds from the liquidation of partnership assets to the discharge of liabilities. The process of winding up and dissolution, in short, is a focusing mechanism that ideally operates to narrow and eventually extinguish partner liability. ${ }^{11}$

The partnership that continues rather than winds up following a withdrawal will continue to incur the full range of liabilities related to the conduct of an ongoing business and will not have the occasion to marshal partnership assets for the purpose of discharging liabilities. The continuity of the partnership, however, does not negate the need to consider liabilities attributable to the dissociated partner's tenure with the partnership in the calculation of the buyout price. As has been discussed, liabilities that are known but contingent may be valued for purpose of estimating the withdrawing partner's share of the liabilities. ${ }^{12}$ There also exists an important class of liabilities that are unknown at the time of dissociation (or time of valuation) but relate, for want of a better term, to the period that a dissociated partner was a member of the partnership. Because they were then unknown, such latent liabilities were not reflected in the buyout price but are properly chargeable to the dissociated partner. ${ }^{113}$ The possibility that a claim unknown at the time of dissociation or buyout will later be asserted against an individual long dissociated from a partnership represents a lingering tie between the partnership and its former partner. This should be a matter of some concern for the former partner, who, because of joint and several liability, may bear more than proportionate responsibility for the obligation if other partners are unable to satisfy their portions of the claim.

A good illustration of the danger of latent liabilities is presented by Redman v. Walters. ${ }^{114}$ Walters, a partner in a law firm, withdrew from the firm one year after it had been retained to pursue a litigation matter. Walters had never met the client and was unaware of the nature of the action. Following Walters's withdrawal, the firm continued to represent the client. Four years after the withdrawal, the client's suit was dismissed for failure to bring it to trial within five years. The client then sued both the firm and Walters for malpractice. Not

110. See id. $\S 802,6$ U.L.A. at 338.

111. On the uses and abuses of liquidation, see Hillman, Misconduct, supra note 17, at 531-34.

112. See supra text accompanying notes $93-95$.

113. For this reason, the dissociated partner who, for one reason or another, avoids a latent liability asserted against the partnership enjoys a windfall.

114. 152 Cal. Rptr. 42 (Cal. Ct. App. 1979). 
surprisingly, Walters was found responsible for the failure of the firm to satisfy an obligation undertaken by the firm while he was a partner (even though he never met the client and knew nothing of the case). Redman serves as a useful reminder of limitations on application of the entity theory to partnerships operating under the principle of joint and several liability. ${ }^{115}$

Even though some Commissioners expressed surprise and dismay with Redman, ${ }^{116}$ RUPA ignores latent liabilities and does nothing to undermine the possibility they will be asserted. Its provisions on buyout price estimates cautiously avoid addressing the nature of liabilities and require indemnification of the dissociated partner against "all partnership liabilities,"117 which presumably includes latent liabilities and therefore is overinclusive indemnification. ${ }^{118}$ RUPA's attempts to define postwithdrawal points at which the dissociated partner's liability terminates speak of the "partnership obligation incurred before dissociation,"119 the "partnership obligation incurred after dissociation," 120 and "transaction[s] entered into . . . within two years after the partner's dissociation." 121 This structure reflects the assumption that liabilities will early reveal the point at which they have been incurred and may readily be treated within the limited classifications outlined. Redman aptly illustrates that claims against a partnership and its members may defy such convenient categorization.

\section{VII}

\section{CONCLUSION}

RUPA allows partners to convert their partnership into an entity that survives partner withdrawals. The option of continuity is a significant change from the ease with which a partnership may be dissolved under the UPA. Whether the change is an improvement of partnership law, however, depends upon whether the UPA's principle of free dissolvability is in need of reform and, if so, whether RUPA's continuity provisions are substantively sound.

This article has focused on the soundness of RUPA's continuity provisions rather than on the more fundamental (and not yet adequately explored) question of whether reform of the UPA's dissolution provisions is necessary at

115. See also Palomba v. Barish, 626 F. Supp. 722, 725 (E.D. Pa. 1985) (Withdrawal from partnership two years prior to alleged malpractice "is of little moment to whether or not [the attorney] can be held liable for the malpractice of his former partners."); Beane v. Paulsen, 97, 26 Cal. Rptr. 2d 486, 491 (Cal. Ct. App. 1993) ("Thus, having been a member of a partnership that contracted with the plaintiff, the defendant continued to be a partner for purposes of that contract until it was discharged."); Thompson v. Gilmore, 88 S.W.2d 75 (Mo. Ct. App. 1994) (Withdrawal and dissolution do not relieve partner of malpractice on case pending at time of dissolution.).

116. See HILLMAN, supra note $22, \S 4.10 .5$ (quoting commissioners' debate and commentary).

117. RUPA $\$ 701$ (d), 6 U.L.A. at 328 (Supp. 1995).

118. Indemnification should be limited to liabilities factored into the buyout price, which is the position taken in earlier drafts of RUPA. See supra notes 93-98 and accompanying text.

119. RUPA § 703(a), 6 U.L.A. at 332 (Supp. 1995).

120. Id.

121. Id. $\S 703(\mathrm{~b}), 6$ U.L.A. at 332. 
all. ${ }^{122}$ In their rush to achieve entity status and continuity of life for partnerships, the drafters of RUPA failed to address adequately, let alone properly balance, the competing interests of partners who withdraw from partnerships, those who continue within partnerships, and other individuals and entities that do business with, or otherwise have claims against, partnerships and their members.

On one level, it is the choices made and reflected in RUPA that are questionable. Deferred buyouts, overinclusive indemnification, rigid deadlines, arcane notice provisions, and a general bias in buyout provisions favoring continuing over dissociated partners are aspects of RUPA that reflect choices. But at least issues of this nature are debatable and, to some extent, were explored in the development of RUPA.

On another level, RUPA's continuity provisions camouflage a fundamental misconception underlying the reforms. According partnerships entity status is the conceptual vehicle used by RUPA to achieve continuity. Yet RUPA's claim that partnerships are entities is bald hyperbole. True implementation of the entity model would eliminate joint and several liability of partners, which is a strong vestige of the aggregate view of partnerships. The continuation of joint and several liability and the prospect of latent liabilities greatly complicate the unwinding of the relationship among partners and render impossible the achievement of true entity status for partnerships under RUPA.

122. The reformers argue, in part, that the UPA's dissolution provisions have been the source of much confusion. See, e.g., Weidner \& Larson, supra note 3, at 3-10. This is true, but it is doubtful that RUPA's response-replete with 120-day deadlines, notices that must be in writing, notices that need not be in writing, use of the term dissociation, and continued but ambiguous use of the term dissolution-will lessen confusion arising from partnership withdrawals. The UPA is also criticized because it necessitates continuation of business through successor partnerships, which creates complications for continuing partners-such as the need to convey property to new partnerships. See id. at 5. But if continuing a business through a new partnership is truly unruly, why did RUPA not simply establish partnership continuity as its default rule, and provide for application of its continuity provisions unless the partners elect otherwise? See supra part II; see also Weidner \& Larson, supra note 3 , at 2 ("The basic idea is that default rules should reflect what most partners would regard as implicit in their partnership agreements."). Indeed, the case cited as illustrative of the need for reform would be decided under RUPA as it was under the UPA unless the partners bargained away RUPA's default provisions. See supra notes 32-39 and accompanying text. 